\title{
Pacific ethnomathematics: pedagogy and practices in mathematics education
}

\author{
LINDA H. L. FURUTO* \\ College of Education, University of Hawai' 'i at Mānoa, 1776 University Avenue, \\ Everly Hall 224, Honolulu, 96822, USA \\ *Email: lindafuruto@post.harvard.edu
}

[Submitted January 2013; accepted February 2014]

\begin{abstract}
In light of the changing ethnic, racial and cultural demographics in US schools, there is a growing need by scholars and practitioners for teaching practices that are informed by cultural knowledge possessed by students. This comes at a time when standardized testing of student achievement has been given a central role in efforts to improve K-12 education such as the Mathematics Common Core State Standards. This article begins with a discussion of ethnomathematics as a conceptual idea, and a practical way of rethinking ideology, content and pedagogy in a rapidly changing climate of diversity. This is followed by a 5-year study on the Ethnomathematics Institute, which provides strategies for implementing promising practices. In Pacific as well as global communities, it is key to understand the role of experiential, values and place-based learning. Through ethnomathematics, we endeavour to build capacity and networks across the USA and Pacific by creating a database of materials and strategies that are relevant, contextualized and sustainable.
\end{abstract}

In light of the changing ethnic, racial and cultural demographics in US schools, there is a growing need by scholars and practitioners for teaching practices that are informed by cultural knowledge possessed by students. In an effort to address issues of equitable and quality education, culturally responsive pedagogy will be explored in diverse Pacific Island communities. A very significant aspect of the social and political reality of the USA may be conveyed by three numbers as outlined in the work of Greer et al. (2009, p. 2):

- Year in which the Caucasian population of the USA is projected to be in the minority: 2042.

- Year in which the Caucasian population of the USA public schools is projected to be in the minority: 2023.

- The proportion of Caucasian teachers in USA schools: $83 \%$.

These figures lend urgency to the question posed by this article, 'What pedagogical practices in mathematics education grounded in ethnomathematics best serve the needs of our students in a rapidly changing climate of diversity?' This article begins with a discussion of ethnomathematics as a conceptual idea, and a practical way of rethinking ideology, content and pedagogy. This is followed by a 5-year study on the Ethnomathematics Institute, which provides strategies for implementing promising practices. This comes at a significant time when testing has come to dominate as students, teachers, administrators and policymakers strive to meet federal and state standards and benchmarks, such as the Mathematics Common Core State Standards (CCSS). CCSS require significantly higher levels of cognitive engagement, including what, how and how much teachers must teach and know. The broader 
principles embedded in these standards have potential to be applied to all other academic learning fields.

\section{Cultural climate and context}

An overview at the international, national and state levels provides a framework to understand the critical value of culturally responsive pedagogy. The Trends in International Mathematics Science Study (TIMSS) and Programme for International Student Assessment (PISA) are longitudinal, international studies that shed light on factors impacting mathematics achievement. The TIMSS resulted from the need for reliable and timely data on the mathematics and science achievement of US students compared to that of students in other countries two decades ago. TIMSS is the most comprehensive and rigorous assessment of its kind undertaken, and in 2011 there were a total of 63 participating countries. Director of TIMSS video studies, James Stigler, concluded that more studies are needed around cultural and political dynamics in schools that mirror wider societal issues (Stigler \& Hiebert, 1988, 1999). Moreover, National Center for Education Statistics studies based on TIMSS results assert that 'instructional practices and expectations of all children regardless of cognitive factors is one of the leading variables in increasing academic achievement' (2003, p. 2).

The PISA is a triennial international assessment that measures 15-year-old students' reading, mathematics and science literacy. It is the product of collaboration between participating countries and economies through the Organization for Economic Cooperation and Development. To date, students representing more than 70 countries and economies have participated in the assessment. According to 2009 PISA data, the USA is ranked 31st with an overall mathematics score of 487, which is below the average PISA mathematics score of 496. The most recent data from 2012 will be published in December 2013 (PISA, 2012). PISA tests are uniquely designed to assess to what extent students can apply their knowledge to real-life situations at the end of compulsory education. Specifically, 2009 PISA assessment found that 'among data on student, community, and institutional factors that could help explain differences in mathematics performance.... access to equitable and quality mathematics resources is key to attaining academic success ... that draw on students' backgrounds and contexts' (PISA, 2012, pp. 3-4).

According to the 2011 US Census Bureau, Pacific Islanders are defined as original peoples of Hawai ‘i, Guam, Samoa and other Pacific Islands. There are roughly 1,371,564 Native Hawaiians and Pacific Islanders who reside within the USA, and $24.9 \%$ of Native Hawaiians or Pacific Islanders of this figure reside in Hawai'i (US Census Bureau, 2011). Thirty percent of Native Hawaiians and Pacific Islanders speak a language other than English at home, and $17 \%$ live at the poverty level compared to $10.6 \%$ of non-Hispanic Caucasians (US Census Bureau, 2011). Hawai 'i's population is among the most diverse in the nation. In fact, Caucasian students make up less than $20 \%$ of the public school enrollment. The breakdown is Hawaiian (25\%), Filipino (19\%), Japanese (12\%), Korean $(8 \%)$ and other ethnic groups. There are a range of schools classified as urban, suburban and rural. The Hawai'i State Department of Education (HIDOE) serves many students in poverty, and the proportion of students on free and reduced lunch is high (29.5\%). Moreover, Hawai' $i$ is the only statewide school district in the nation, and operates a single public state higher education system, the University of Hawai'i System (UHS).

The data and context make Hawai' $i$ a valuable study, and provides a significant lens into the future of diversity in the USA. On a positive note, the National Center for Education Statistics shows that the average scaled mathematics score for 8th grade students in the State of Hawai' $i$ in 2011 is higher than the average scaled score of 274 in 2009 (NAEP, 2012). However, while State of Hawai'i students are gradually improving in mathematics, a review of the disaggregated data reveals the Native Hawaiian 
and Pacific Islander students perform significantly below their Caucasian and Asian peers in both mathematics and science (NAEP, 2012).

Among research studies conducted, Greenfield (1996) argues that this gap is due in part to "the incompatibility of the traditional Western system of education with the values and practices of Hawaiian culture' (p. 923). Additional factors include: lowered expectations and learning goals for low-income and minority youth, limited use of student-centered and problem-based teaching strategies, inequities in instruction, and limited resources and time (Duschl et al., 2007). Mathematics education needs to address the achievement gap among diverse groups of students, and more transformative ways need to draw on the strengths of students' cultural backgrounds (Goetzfridt, 2008).

The Hawai'i State Department of Education is doing its part to raise mathematics standards by revising mathematics benchmarks, strengthening quality education and raising the graduation requirements as outlined in the Hawai'i State Department of Education Strategic Plan 2011-2018 (HIDOE, 2012). Specifically, the requirements for the Hawai' $i$ High School Diploma beginning with the class of 2016 are a minimum of three credits in mathematics, including algebra I and geometry. In the past, many students taking algebra II went on to major in science, technology, engineering and mathematics (STEM) fields. However, now the algebra II classrooms are comprised students who have a greater breadth of learning styles. We need to improve the pipeline leading to career and college ready mathematics so that we not only increase the number of students earning degrees, but more specifically increase the number of degrees as detailed in the University of Hawai'i System Strategic Outcomes \& Performance Measures, 2008-2015 (UH IRO, 2013). According to University of Hawai'i Executive Vice President of Academic Planning and Policy Linda Johnsrud, the mental ability to do the process that comes with doing mathematics is paramount. Specifically, 'We don't need more human calculators; we need people who can think' (Johnsrud, L., personal communication, 6 February 2013).

In Pacific as well as global communities, it is key to understand how experiential and place-based learning are contextualized to the sea and navigation. Pacific Islanders relied heavily on voyaging to survive in the past, produced a technology that still resonates today, and exemplify the importance and processes of cultural conceptualizations (Baybayan et al., 1987; Chauvin, 2000). The National Council of Teachers of Mathematics asserts, 'Mathematics performance and learning of groups that have traditionally been underrepresented in mathematics fields can be improved by interventions that address social, affective, and motivational factors' (2008, p. 6). These types of teaching and learning strategies lead to higher mathematics performance as we have seen through ethnomathematics and culturally responsive pedagogies (NCTM, 2008).

\section{Ethnomathematics and culturally responsive pedagogy}

Over the past three decades, there has been recognition that among indigenous peoples there are other non-Western forms of wisdom. This work has had a variety of labels including, 'culturally appropriate' (Au \& Jordan, 1981), 'culturally congruent' (Mohatt \& Erickson, 1981), 'culturally responsive' (Cazden \& Leggett, 1981; Howard \& Terry, 2011) and 'culturally compatible' (Jordan, 1985; Vogt et al., 1987). According to Gay (2000) and Ladson-Billings (1995), there is tremendous value in nontraditional knowledge that backs societal structures through research, theory and practice. Furthermore, the UCLA Center X has documented that 'Culture matters when it comes to teaching and learning. Every child enters a classroom with rich cultural knowledge and lived experiences that help them learn each day' (2008, p. 1). D'Ambrosio (2001) explains that an important component of ethnomathematics is to reaffirm the individuality and identity of students through education.

Defined as the intersection of culture, historical traditions, sociocultural roots and mathematics, among others, ethnomathematics encourages the investigation and adaptation of these concepts within 
and outside of the classroom. The goal is to acknowledge cultural systems and frameworks that have existed since the beginning of time and to help educators discover pathways that foster student engagement through conceptualizing and supporting new approaches to learning mathematics. A strong component is finding relevance in real-world applications through physical, environmental, spiritual and cultural capacities (Jonsson, 1988; Gutstein \& Peterson, 2006).

As an example, the Hōkūle'a, 'star of gladness', is a double-hulled Pacific Island canoe of the Polynesian Voyaging Society that connects students to cultural and historical traditions and is circumnavigating the globe from 2013 to 2017. The Hōkūle'a is internationally renowned for the role it has played in rekindling the Pacific Island tradition of non-instrument way-finding techniques that include celestial navigation such as the sun, moon and stars based in mathematical principles. Hōkūle'a has traveled 140,000 nautical miles to locations such as Tahiti, Rapa Nui, Marquesas Islands, Samoa, Micronesia, Japan and the US mainland. Thousands of children around the world have connected to the Hōkūle'a over the past four decades (Finney et al., 1986). Hōkūle'a is a vehicle to bridge indigenous models of mathematics at the local and global levels, and the author will be part of the first leg of the international voyage from Hawai' $i$ to Tahiti in 2014. According to Polynesian Voyaging Society President and Hōkūle'a master navigator Nainoa Thompson,

Our ancestors sailed across a vast ocean, one third of the earth's surface, and to accomplish this great feat they needed mathematical vision and tools to see islands over the horizon, the ability to plan intentional voyages of discovery, the discipline to train physically and mentally, the courage to take risks, and a deep sense of aloha to bind the crew together during the voyage. The values worked in the past and they will work today (Thompson, N., personal communication, 5 October 2013).

Hōkūle'a is a powerful vehicle to explore real-world applications of mathematics in Hawaiian and global communities, and represents resourcefulness, inventiveness, wisdom grounded in the past, and hope for the future.

\section{Theoretical approaches}

The strategies of ethnomathematics and culturally responsive pedagogy are grounded in scientific research and three primary theoretical approaches: respecting and understanding social and cultural capital, engaging effective models of professional development and incorporating values-based education. Ethnomathematics uniquely unites a broad cluster of ideas ranging from distinct numerical and mathematical systems with identity, including race/ethnicity, socioeconomic class and special needs (D'Ambrosio, 2001). D'Ambrosio explains that it is generally not common to connect mathematics and identity. When a link is acknowledged, it is often a brief multicultural activity removed from the students in the class.

First, an important component of mathematics education should be to reaffirm the individuality of students through social and cultural capital. The National Council of Teachers of Mathematics asserts, 'Mathematics performance and learning of groups that have traditionally been underrepresented in mathematics fields can be improved by interventions that address social, affective, and motivational factors' (2008, p. 6). As schooling is experienced in this manner, students and teachers develop a greater respect for other ways of processing, assessing and utilizing content skills.

Educational research has shown a relationship between student success and an increased role for context in the curriculum; for example, 'recognition of diverse knowledge systems, use of local funds of knowledge, and the value of community understandings through social and cultural capital' (Gonzalez et al., 2005, p. 15). Lipka \& Adams (2004) and Nelson-Barber \& Lipka (2008) show that indigenous student performance improves when cultural and linguistic practices are employed 
in the classroom. There is a call to focus on capacity building and a respect for community-based structures (Uehara \& Flores, 2000; Low, 2010).

Second, according to the Harvard University Achievement Gap Initiative, 'Professional development through a socio-ecological and cultural approach is necessary to frame issues and distill implications for decision makers in an emergent movement for excellence with equity' $(2008, \mathrm{p}$. 2). There is a connection between student achievement and teacher quality, which is strengthened through relevant curriculum, high expectations, and a robust community and classroom environment (Kyselka, 1987; Powell \& Frankenstein, 1997; Stigler \& Hiebert, 1999). The Pacific Standards for Excellence in Professional Development were designed by Pacific Resources for Education and Learning (PREL, 1995). These were adapted from the National Council of Teachers of Mathematics' Professional Standards for Teaching Mathematics and the National Research Council's National Science Education Standards to provide criteria for designing and evaluating pre- and in-service mathematics and science programmes in the Pacific. The Pacific Standards for Excellence in Professional Development were built around essential characteristics for professional development, and include: (a) experience good teaching, (b) strengthen content knowledge, (c) understand students as learners, (d) build pedagogical knowledge and (e) develop as members of the professional community.

Third, values-based education through a variety of teaching and learning strategies is supported by the work of Astin \& Oseguera (2005) and Hurtado \& Schoem (2001). Within Pacific Island groups, including Melanesia, Micronesia and Polynesian, we celebrate cultural heritage and diversity, honour common values, foster a community of students and educators, encourage global sustainability and catalyze positive change (Beckwith, 1932; Au \& Jordan, 1981; Thomas, 1987). The following are main principles that reflect the values, cultures and traditions of the populations we endeavour to serve. They inform and direct educational efforts, and focus on promoting a positive learning environment: (a) navigation (vision, exploration, education); (b) honouring elders (tradition, heritage, family, our first people); (c) environment (our sacred earth); (d) island living (our Pacific 'ohana and multiethnic community').

According to ethnomathematics scholar Ascher, 'Mathematical ideas involve number, logic, and in particular, organization of these into value structures' (1998, p. 185). In the Pacific, we have learned through ethnomathematics the important role of cultural values, and how deeply these impact teaching, learning and curriculum (Finney, 1979; Baybayan et al., 1987; Chauvin, 2000).

\section{Promising practices: ethnomathematics institute}

Now in its sixth year, the Ethnomathematics Institute is an example of promising practices, and explores issues of equitable and quality education through culturally responsive pedagogy based on the Mathematics CCSS. The Ethnomathematics Institute is supported by grants from the National Science Foundation and US Department of Education, and the author is the principal investigator. The underlying themes are how cultural values affect teaching, learning and curriculum, and the role of mathematics education in the schooling process dynamics. The Ethnomathematics Institute brings together major stakeholders throughout the Pacific including the University of Hawai'i System, Hawai'i State Department of Education, Hawai'i P-20 Partnerships for Education, Pacific American Foundation, Pacific Resources for Education and Learning, and Polynesian Voyaging Society to support professional development for teachers.

The goals and objectives of the Ethnomathematics Institute include:

- Objective 1: Align culturally responsive mathematics with Mathematics CCSS benchmarks.

- Objective 2: Explore connections to mathematics courses through curriculum design, implementation and assessment. 
- Objective 3: Establish campus-community partnerships in the State of Hawai'i and Pacific for sustainable classroom and community networks.

Through an orientation, series of professional development workshops and a 1-week summer institute, educators from across the State of Hawai ' $i$ and Pacific design and implement mathematics lesson plans grounded in ethnic, historical and cultural diversities of our island homes. The resulting research and practicum-based textbook is used by current educators to supplement curriculum, and future teachers as training material in aligning CCSS. This model aids teachers in implementing culturally responsive mathematics pedagogy and connecting classroom curriculum to real-world applications.

The project Ethnomathematics Institute involves 25 participants, including 20 public, public charter, private and parochial school in-service educators, and 5 pre-service STEM majors selected through a competitive application process each year. The professional development programme focuses on preparing, training and recruiting high-quality teachers. Each of the 25 in-service and pre-service educators implement their mathematics lesson plan in at least one K-12 class. Thus, annually 625 K-12 students are impacted by the Ethnomathematics Institute ( 25 educators * 25 K-12 students/ class $=625 \mathrm{~K}-12$ students). The institute addresses identified statewide priorities for developing and supporting a high-quality teaching force by helping teachers discover new pathways that foster student engagement and achievement through the Mathematics CCSS.

Research and evaluation conducted during the project over the past 5 years offers insights into effective mathematics instruction and pedagogy to support the high needs area of mathematics and science teachers in the Pacific. Past participants include educators from islands in Polynesia, Melanesia and Micronesia. Through the Ethnomathematics Institute, we strive to build on the strengths that students have developed in their own contexts/communities, using these as bridges to the knowledge, skills and abilities students will need for broader competence in society. The Ethnomathematics Institute has been featured in articles, press releases and other forms of local and national media such as the National Council of Teachers of Mathematics (2011), Mathematical Association of America (2010), Hawai'i Public Radio (2010), Pacific Business News (2007) and University of Hawai'i Mālamalama Magazine (2010).

\subsection{Objective 1: align culturally responsive mathematics with CCSS}

Classroom instruction is enhanced by experiential and service learning at locations such as the Hawai ' $i$ Institute of Marine Biology's Coconut Island, Mokauea Island Fishing Village, sailing with the Hōkūle'a around the Hawaiian Islands and US National Historical Park at Kalaupapa. Through designing and implementing mathematics lesson plans connected to CCSS standards and benchmarks, the institute is committed to making high-quality professional learning relevant, classroom-focused and sustainable.

The locations were selected based on the theoretical approaches of respecting and understanding social and cultural capital, engaging effective models of professional development and incorporating values-based education. Mokauea Island is the site of O'ahu's last Hawaiian fishing village, and one of only two left in Hawai' $i$ where hundreds of villages thrived in pre-European times. Through an experiential learning environment, participants take an active role in preserving, protecting and caring for marine life. Participants help restore the fishing village, and in the process learn about mathematical skills and the perpetuation and practice of fishing, seafaring and maintaining healthy viable oceans. The Hawai ' $i$ Institute of Marine Biology is a world-renowned research institute located on 64 acres of open ocean and Coconut Island. Participants investigate intersections of natural resources, environmental conservation and tropical marine science in their Hawaiian backyard. With a 
legacy of ocean exploration as its foundation, the Polynesian Voyaging Society is committed to undertake voyages of discovery, respect and perpetuate heritage through practice, and promote learning which integrates voyaging experiences and values into quality education. Through sailing around O'ahu by traditional techniques, we learn how mathematics is a tool to learn about time, space and place. The US National Historical Park at Kalaupapa, Moloka'i was once a leprosy community in isolation, and now serves as a place for education and contemplation. Here, past suffering has given way to personal pride about accomplishments made in the face of great adversity. Kalaupapa is a place where holistic education is emphasized because of its human history, natural history and physical beauty. Through first-hand experiences on land and sea, participants come to understand how these themes impact critical thinking, quantitative literacy and lifelong learning.

Upon visiting these significant sites and learning about mathematical relationships, one student commented:

What made this trip interesting is the fact that we were taught how to use math formulas that we had learned in class in a real world situation, such as determining the dimensions of each canoe, location, and distance. It was interesting to learn about the historical aspects of the voyage. I want to learn math so I can learn more about the great feats of my ancestors. All in all, this was definitely a once in a lifetime opportunity that I'm glad I didn't miss (Bello, M., personal communication, 27 October 2010).

Specific content areas are drawn from the Mathematics CCSS. The CCSS Mathematics Practices describe varieties of expertise that mathematics educators at all levels should seek to develop in their students. Professional development includes making connections between curriculum design, assessment and mathematics practices to instruction. Mathematics Practice 1 is centered on making sense of problems and persevering in solving them, and Mathematics Practice 2 is to reason abstractly and quantitatively in problem situations. For example, these are explored through a bioacoustics lab at the Hawai' $i$ Institute of Marine Biology, where participants use computer simulations to track the impact of sound waves on coral reefs. They map amplitude, period, frequency and wavelength, among other content knowledge, and learn about natural resources in the physical environment. Mathematics Practice 4 is modelling with mathematics, and is aligned with the goals of this project to apply mathematics to solve problems arising in everyday life and society.

\subsection{Objective 2: explore connections to culturally responsive mathematics courses through curriculum design, implementation and assessment}

Institute participants work with partners on exploring connections to culturally responsive mathematics through curriculum design. The participant experience is enhanced through a culturally relevant curriculum in geometry, algebra, statistics, marine biology, physical science, technology and engineering. For example, vectors are discovered through first-hand sailing and navigating voyaging canoes, the Hawaiian star compass is used as a guide to study the trigonometric unit circle and apply half-angle and double angle formulas, analytic geometry and engineering are investigated by maintaining and caring for voyaging canoes, and information technology is studied while comparing sequences and coding to traditional Hawaiian Makahiki games. Specifically, while at Mokauea Island Fishing Village, participants examine analytic geometry in the fishpond. They explore fundamental properties of ellipses as they pertain to ecosystems, biodiversity and the role of water in Earth's surface processes which are also closely connected to the Next Generation Science Standards (NGSS).

Over the course of the project year, teachers work in teams on culturally responsive mathematics lesson plans. The teams are organized by grade level and content topic, such as navigation and 
wayfinding, indigenous knowledge systems and relationships in ecosystems. Through designing and implementing mathematics lesson plans, participants interact with effective models of professional development and help tailor educational efforts to meet the needs of their students. The resulting deliverable is a textbook with mathematics lesson plans that have been distributed throughout the State of Hawai' $i$ and Pacific for use in teacher education programmes and beyond. The curriculum textbook engages current and prospective teachers by continuing dialogue on significant themes in STEM education, supplementing curriculum and enriching teacher training materials.

\subsection{Objective 3: establish campus-community partnerships for sustainable classroom and community networks}

The third objective is to help teachers discover new pathways that foster student engagement and achievement beyond the institute throughout the Pacific. The Polynesian Voyaging Society has helped guide connections between higher education, K-12 education, research institutions and communitybased organizations, through the worldwide voyage. The mission of Hōkūle 'a's Worldwide Voyage is to navigate towards a healthy and sustainable future for ourselves, our home - the Hawaiian Islandsand our Island Earth through voyaging and new ways of learning. The core message is to mālama (care for) Island Earth - the natural environment, children and humankind. The mathematics lesson plans will be taken to ports as the Hōkūle'a canoe circumnavigates the globe (please see Fig. 1 Hōkūle'a Worldwide Voyage Sail Plan).

Research shows that building successful partnerships with educators, policymakers, research institutions and community-based organizations is a critical component of academic achievement. Performance of groups that have traditionally been underrepresented in STEM fields can be improved by interventions that are cultivated through building partnerships with key stakeholders (Greer et al., 2009). Within the Ethnomathematics Institute, partnerships include the University of Hawai'i System, Hawai 'i State Department of Education, Hawai'i P-20 Partnerships for Education, Pacific American Foundation, Pacific Resources for Education and Learning and Polynesian Voyaging Society. These represent the primary voices promoting educational, social and development efforts in the Pacific.

\subsection{Project evaluation}

Programme implementation has occurred in two phases, professional development provided to teachers and classroom implementation of content and pedagogy learned in the professional development. Central evaluation questions include: To what extent was the project implemented successfully?; What kinds of adaptations occurred?; and How did participation impact teachers' instructional practices in ethnomathematics and culturally responsive pedagogy? Success has also been measured by an increased number of participants, community partners, and progression and retention in STEM courses.

Data have been collected on the extent and quality of the process and the potential for impacting teachers' professional growth, instructional practice and sustainability of the programme. These have allowed us to evaluate shifts in use of terminology, discussion of teaching practices, and attitudes towards mathematics and culture-based instruction.

There has never been a more important time to cultivate sustainable conditions that advance student success in college. Student outcomes rely on the thoughtful design of content integrated with cultures, places and practices. The successes have been tremendous at the University of Hawai 'i-West O'ahu (note: the principal investigator was previously employed as an Associate Professor of Mathematics at 


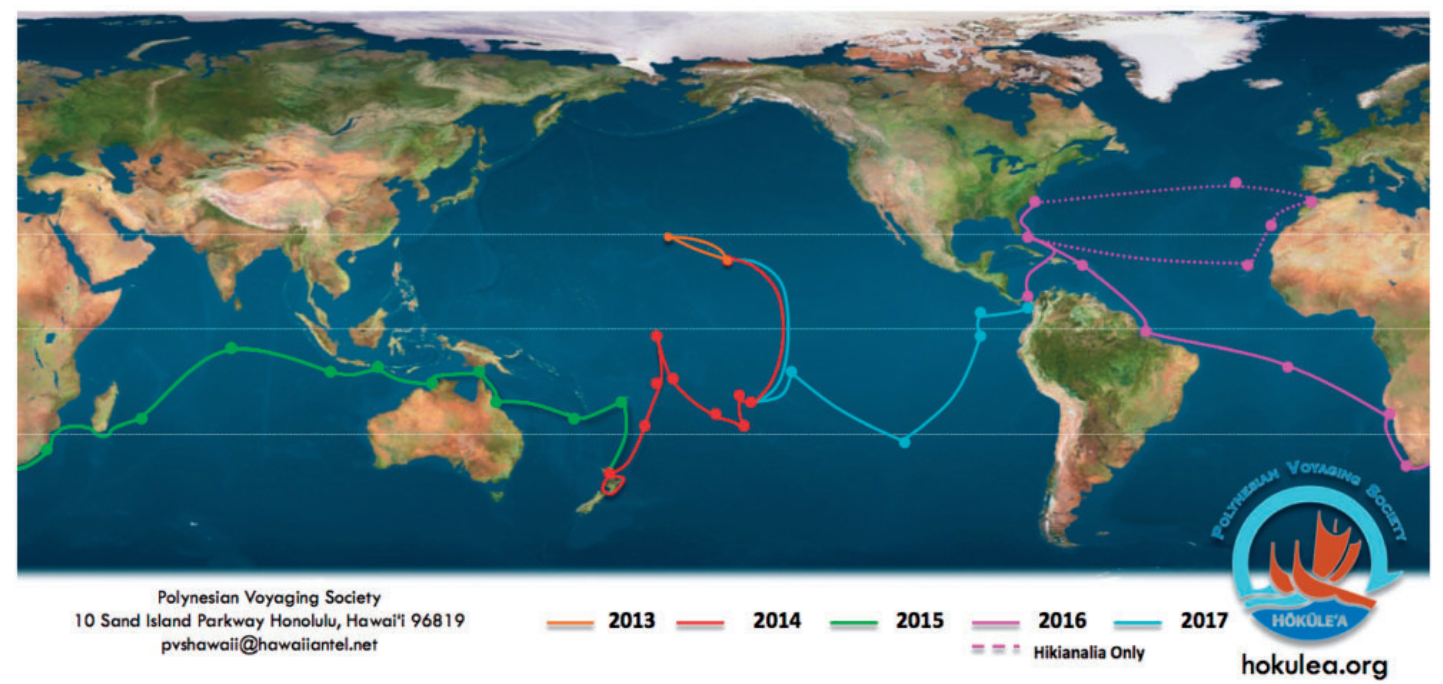

FIG. 1. Hōkūle'a Worldwide Voyage Sail Plan.

Source: Polynesian Voyaging Society. This figure appears in colour in the online version of Teaching Mathematics and its Applications.

the University of Hawai ' $\mathrm{i}-\mathrm{West} \mathrm{O}$ 'ahu), and we continue to meet and overcome challenges. In the past couple of years, we have worked to develop a bachelor of arts degree in mathematics education to work towards fulfilling the teacher shortage in the State of Hawai' $i$ at the middle and secondary levels. Through implementing promising practices, we have seen the proportion of underrepresented students double in University of Hawai 'i-West $\mathrm{O}^{`}$ 'ahu mathematics courses, particularly for Native Hawaiian and Pacific Islander populations.

According to the University of Hawai'i Institutional Research Office (UH IRO), performance measures over the past year include a $68.6 \%$ increase in the number of students enrolled in mathematics courses at the University of Hawai ' $\mathrm{i}-\mathrm{West} \mathrm{O}$ 'ahu (UH IRO, 2013). The advancement of these students 1-2 course levels necessitated the development of four new mathematics courses (i.e., MATH 241-244 Calculus I-IV). The overall passing rate has almost doubled from $42.8 \%$ to $80.6 \%$, far above the average passing rate for the University of Hawai'i System (UH IRO, 2013). The partnerships formed and promising practices developed provide a platform to continue to nurture and develop the Ethnomathematics Institute to provide high-quality student-centered, classroom-focused and sustainable services.

\section{Further discussion}

Culturally responsive pedagogies and teaching are essential given the increasing ethnic, social and cultural diversity in today's US schools to meet the call of federal and state policies. Currently, 63 of the 100 largest school districts have larger numbers of culturally diverse students than Caucasian students, and the year in which the Caucasian population of the US public schools is projected to be in the minority is 2023. Given the diversity of schools, teaching practices that build on what students know are essential for overall school success given the central role of standardized, large-scale tests of 
student achievement to improve K-12 education such as the Mathematics CCSS. CCSS require significantly higher levels of cognitive engagement, including what, how and how much teachers must teach and know.

Teacher preparation begins the process of developing effective teachers, and when connected to continuing professional development opportunities and comprehensive evaluation, creates a system of career-long support. Educators need support throughout their careers to hone their practices in order to teach standards, meet the needs of a diverse set of students and create a positive classroom culture. Professional learning should center on increasing teachers' content knowledge, while giving time to train and receive feedback on effective student instructional strategies.

The Ethnomathematics Institute views teaching as a rich and multifaceted endeavour that is built on a wide range of knowledge and skills about students, pedagogy and culture. The intersection of each of these domains in an innovative approach based on real-world applications is critical to engage students in contextualized, sustainable learning. The broader principles embedded in these standards have potential to be applied to all other academic learning fields. When all students' inventions, experiences and applications of mathematics are realized and respected, they are given equal opportunity for access and achievement.

\section{Funding}

National Science Foundation and US Department of Education, in part.

\section{REFERENCES}

Ascher, M. (1998) Ethnomathematics: A Multicultural View of Mathematical Ideas. New York, NY: Chapman \& Hall/CRC.

Astin, A. \& Oseguera, L. (2005) Degree Attainment Rates at American Colleges and Universities. Los Angeles, CA: Higher Education Research Institute.

Au, K. \& JoRdAN, C. (1981) Teaching reading to Hawaiian children: finding a culturally appropriate solution. Culture and the Bilingual Classroom: Studies in Classroom Ethnography (H. Trueba, G. Guthrie \& K. Au eds). Rowley, MA: Newbury House, pp. 69-86.

Baybayan, C., Finney, B., Kilonsky, B. \& Thompson, N. (1987) Voyage to Aotearoa. J. Polynesian Soc., 96, 161-200.

Beckwith, M. (1932) Kepelino's Traditions of Hawaii. Honolulu, HI: Bernice P. Bishop Museum.

Bello, M. (2010) Personal communication, 27 October 2010.

CAzden, C. \& LegGett, E. (1981) Culturally responsive education: recommendations for achieving Lau remedies II. Culture and the Bilingual Classroom: Studies in Classroom Ethnography (H. Trueba, G. Guthrie \& K. Au eds). Rowley, MA: Newbury House, pp. 69-86.

Chauvin, M. (2000) Useful and conceptual astronomy in ancient Hawaii. Astronomy Across Cultures Hist. Non-Western Astronomy, 1, 91-125.

D’Ambrosio, U. (2001) Ethnomathematics Link between Traditions and Modernity. Rotterdam, Netherlands: Sense Publishers.

Duschl, R., Schweingruber, H. \& Shouse, A. (2007) Taking Science to School: Leaning and Teaching Science in Grades $K$-8. Washington D.C.: National Research Council Education.

ERnst, C. (2010) Ethnomathematics makes difficult subject relevant. University of Hawai'i Mālamalama Magazine (see http://www.hawaii.edu/malamalama/) [accessed 23 March 2014].

Finney, B. (1979) Hōkūle'a the way to Tahiti. New York, NY: Dodd, Mead, \& Company. 
Finney, B., Kilonsky, B., Somseon, S. \& Stroup, E. (1986) Re-learning a vanishing art. J. Polynesian Soc., 95, 41-90.

Furuto, L. (2010) Studying the cultural nature of mathematics [Interview by B. Markus]. (see http://www. hawaiipublicradio.org/) [accessed 23 March 2014].

GAY, G. (2000) Culturally Responsive Teaching: Theory, Research, \& Practice. New York, NY: Teachers College Press.

Goetzfridt, N. (2008) Pacific Ethnomathematics a Bibliographic Study. Honolulu, HI: University of Hawai'i Press.

Gonzalez, N., Moll, L. \& Amanti, C. (2005) Funds of Knowledge: Theorizing Practices in Households, Communities, and Classrooms. New York, NY: Routledge Press.

Greenfield, T. A. (1996) Gender, ethnicity, science achievement, and attitudes. J. Res. Sci. Teach., 33, 901-933.

Greer, B., Mukhodpadhyay, S., Powell, A. \& Nelson-Barber, S. (2009) Culturally Responsive Mathematics Education. New York, NY: Routledge Press.

Gutstein, E. \& Peterson, B. (2006) Rethinking Mathematics: Teaching Social Justice by the Numbers. Milwaukee, WI: Rethinking Schools, Ltd.

Harvard University AchiEVEment Gap Initiative (2008) Raising Achievement and Closing Gaps in Whole School Systems: Recent Advances in Research and Practice. Boston, MA: Harvard University Graduate School of Education Press.

Hawai 'i State Department of Education (HIDOE) (2012) Hawai $i$ Department of Education Strategic Plan 2011-2018, 2012 Update. Honolulu, HI: Hawai'i Department of Education.

Howard, T. \& Terry, C. (2011) Culturally Responsive Pedagogy for African American Students. Los Angeles, CA: Center X Change.

Hurtado, S. \& Schoem, D. (2001) Intergroup Dialogue: Deliberative Democracy in School, College, Community, and Workplace. Ann Arbor, MI: University of Michigan Press.

JohnsRud, L. (2013) Personal communication, 6 February 2013.

Jonsson, E. (1988) The Carolinian cane as a navigation instrument. Pacific Island Focus, 1, 14-33.

Jordan, C. (1985) Translating culture: from ethnographic information to educational program. Anthropol. Educ. Quart., 16, 105-123.

Kenschaft, P. (2011) Ethnomathematics and mathematics professors. Math. Assoc. America Focus, 31, 8-9.

Kyselka, W. (1987) An Ocean in Mind. Honolulu HI: University of Hawai'i Press.

LAdson-Billings, G. (1995) But that's just good teaching! The case for culturally relevant pedagogy. Theory Pract., 34, 159-165.

LiPKA, J. \& AdAms, B. (2004) Culturally Based Math Education as a Way to Improve Alaska Native Students' Mathematics Performance. Athens, Greece: Appalachian Center for Learning, Assessment, and Instruction in Mathematics.

Low, M. (2010) Teachers and Texts: Judging What English Language Learners know from What they Say. London, England: Multilingual Matters.

Монатt, G. \& Erickson, F. (1981) Cultural differences in teaching styles in an Odawa school: a sociolinguistic approach. Culture and the Bilingual Classroom: Studies in Classroom Ethnography (H. Trueba, G. Guthrie \& K. Au eds). Rowley, MA: Newbury House, pp. 105-119.

National Assessment for Educational Progress (NAEP) (2012) The Nation's Report Card Mathematics 2011. Washington, D.C.: US Department of Education.

National Council of Teachers of Mathematics (2008) Foundations for Success: The Final Report of the National Mathematics Advisory Panel. Reston, VA: National Council of Teachers of Mathematics Pub. 
Nelson-Barber, S. \& LipKa, J. (2008) Rethinking the case for culture-based curriculum: Conditions that support improved mathematics performance in diverse classrooms. Language, Curriculum \& Community in Teacher Preparation. Mahwah, NJ: Lawrence Erlbaum Associates, Inc., pp. 99-123.

Pacific Resources for Education and Learning (PREL) (1995) Pacific Standards for Excellence in Professional Development. Washington, D.C.: US Department of Education.

Powell, A. \& Frankenstein, M. (1997) Ethnomathematics: Challenging Eurocentrism in Mathematics Education. New York, NY: State University of New York Press.

Programme for International Student Assessment (PISA) (2012) PISA 2011 Results. (see http://www.pisa. oecd.org/) [accessed 13 October 2013].

Shimogawa, D. (2007) Math students will use voyaging techniques. Pacific Business News. (see http://www. bizjournals.com) [accessed 23 March 2014].

Stigler, J. \& Hiebert, J. (1999) The Teaching Gap: Best Ideas from the World's Teachers for Improving Education in the Classroom. New York, NY: Free Press.

Stigler, J. \& Hiebert, J. (1988) Teaching is cultural. American Educ., 22, 4-11.

Thomas, S. (1987) The Last Navigator. New York, NY: Henry Holt and Co.

Thompson, N. (2013) Personal communication, 5 October 2013.

Uehara, D. \& Flores, J. (2000) Diversity in Action: Improving Educational Research in the Pacific Region Briefing Paper. Honolulu, HI: Pacific Resources for Education and Learning.

University of California, Los Angeles Center X (2008) The Role that Teachers' Beliefs about Mathematics Play in Bringing about Change in the Elementary Mathematics Classroom: A Professional Development Model. Los Angeles, CA: UCLA Graduate School of Education and Information Studies Press.

University of Hawai'i Institutional Research Office (UH IRO) (2013) MAPS Enrollment Projections (see http://www.iro.hawaii.edu/maps/mltitles.asp) [accessed 13 October 2013].

US Census Bureau (2011) The Native Hawaiian and Other Pacific Islander Population. (see http://www. census.gov/) [accessed 18 August 2013].

Vogt, L., Jordan, C., \& Tharp, R. (1987) Explaining school failure, producing school success: two cases. Anthropol. Educ. Quart., 18, 276-286.

Linda H. L. Furuto is an Associate Professor of Mathematics Education at the University of Hawai 'i at Mānoa. Dr Furuto completed her Ph.D. at the University of California, Los Angeles, and master's degree at Harvard University. She has been a Visiting Scholar of Mathematics at the University of Tokyo, worked with students in the Boston public school system as a research-practitioner in Harvard University's Inventing the Future Project, taught mathematics and music at the Technical College in Fiji, collaborated with the US Department of State on the World Exposition in Japan, and designed educational programmes for the Polynesian Voyaging Society's Worldwide Voyage 2013-2017. Dr Furuto's research interests include quantitative research methods, policy analysis, mathematics achievement, abstract algebra, and educational access and equity. 